\title{
Serum immunoreactive gastrin: specificity for rheumatoid arthritis, bimodality of distribution, and failure of effect of anti- inflammatory drugs
}

\author{
P. J. ROONEY, D. M. GRENNAN, R. D. STURROCK, P. M. BROOKS, AND \\ W. CARSON DICK \\ From the Centre for Rheumatic Diseases and University Department of Medicine, Royal Infirmary, Glasgow
}

\begin{abstract}
Rooney, P. J., Grennan, D. M., Sturrock, R. D., Brooks, P. M., and Dick, W. C. (1976). Annals of the Rheumatic Diseases, 35, 40-45. Serum immunoreactive gastrin: specificity for rheumatoid arthritis, bimodality of distribution, and failure of effect of anti-inflammatory drugs. A significant rise in immunoreactive gastrin in a proportion of patients with rheumatoid arthritis is confirmed. Such a rise does not seem to occur in other inflammatory or tissue destructive diseases. The patients with raised immunoreactive gastrin appear to form a separate population but the factors determining this separation remain obscure. Anti-inflammatory drugs, at least during short-term administration have no influence on immunoreactive gastrin concentrations.
\end{abstract}

We recently reported that in a proportion of patients with 'definite' or 'classical' rheumatoid arthritis the serum immunoreactive gastrin (IRG) concentration was markedly raised; often in fact to a level which is normally associated with the Zollinger-Ellison syndrome (Rooney and others, 1973b). In further work investigating the mechanism of this rise we showed that serum immunoreactive gastrin levels rose during the induction of adjuvant arthritis in rats (Rooney and others, 1973a), placing the effect firmly within the inflammatory process. More recently we showed a remarkably close correlation between gastric acid output and serum immunoreactive gastrin levels during pregnancy and the puerperium, documenting both a rise in IRG levels in late pregnancy and early puerparium and marked hypergastrinaemia of the immediate neonatal prriod when severe gastric hyp racidity is common (Rooney and others, 1975b).

In studies with the liquorice derivative, carbenoxolone sodium, which is unique in possessing both anti-inflammatory and ulcer-healing proparties, we were able to show a significant rise in immunoreactive secretin concentrations which paralleled the expacted changes in plasma electrolytes and acid-base concentrations but were unable to show any consistent change in serum IRG concentrations (Rooney and others, 1974).
In the present paper we report further studies of IRG concentration in an extended group of patients with rheumatoid arthritis in which there is evidence of a bimodal distribution of IRG. We have also compared the IRG concentrations obtained in normal subjects and in patients with rheumatoid arthritis with IRG levels measured in other inflammatory and tissue-destructive diseases, the results of which tend to focus our attention upon the 'disease' rheumatoid arthritis. In addition we report the results of serum IRG concentrations measured before and after the administration of standard anti-inflammatory drugs given alone to patients with rheumatoid arthritis.

Patients and methods

RHEUMATOID ARTHRITIS

152 patients with 'definite' or 'classical' rheumatoid arthritis according to the criteria of the American Rheumatism Association (Ropes and others, 1959), were studied, 40 males and 112 females, mean age 56.37 years (range 25 82 years). The mean duration of the disease was 12.57 years (range $3-42$ years) and all had a peripheral, symmetrical, inflammatory polyarthritis (mean \pm SEM articular index $19 \cdot 8 \pm 1.58$ score units) and erosions on joint $x$-ray. Of the 152 patients, 125 were seropositive for rheumatoid factor, 47 had subcutaneous nodules, and 37 had 
Table I Visceral complications of rheumatoid arthritis encountered in 23 of 152 patients studied

\begin{tabular}{ll}
\hline & $\begin{array}{l}\text { No.of } \\
\text { patients }\end{array}$ \\
\cline { 2 - 2 } Complication & 5 \\
Cutaneous vasculitis & 4 \\
Neuropathy & 4 \\
Lymphadenopathy & 3 \\
Atlantoaxial subluxation & 3 \\
Felty's syndrome & 2 \\
Pleural effusion & 2 \\
Pericarditis & 1 \\
Pulmonary fibrosis & 1 \\
Amyloidosis & 1 \\
Digital arteritis and gangrene & 1 \\
Brown-Kelly Patterson oesophageal web & 1 \\
\hline
\end{tabular}

documented evidence of Sjøgren's syndrome (Whaley and others, 1973). In none of these patients was there evidence of any coincident disease of another major system, although 23 patients had a visceral complication (Table I). All of these patients had received or were receiving one or more of a diverse collection of nonsteroidal anti-inflammatory drugs, 6 were receiving or had received chrysotherapy, and 34 were receiving longterm low dose $(<7.5 \mathrm{mg}$ prednisolone or equivalent daily) corticosteroid therapy. At the time of withdrawal of serum for IRG estimation these patients were all assessed by the determination of articular index, pain index, grip strength, ring sizes, and duration of morning stiffness by a single observer whose intra- and interobserver errors have been documented by an entirely standardized, methodology reported elsewhere (Lee and others, 1973).

SYSTEMIC LUPUS ERYTHEMATOSUS (SLE)

Fifteen patients, 14 females, 1 male, with established SLE were studied. Mean age was 44 years (range 28-51 years). Mean duration of disease was 11.5 years (range 2-25 years). All had positive tests for antinuclear factor in titres $>1$ in 64 (mean reciprocal titre \pm SEM 475·2 \pm 107.2). Of the entire group, four patients had clinical evidence of renal involvement. No patient in this group was shown to have raised levels of DNA binding $(>50 \%)$ at the time of study. Five patients were receiving low-dose corticosteroid therapy ( $<7.5 \mathrm{mg}$ prednisolone or equivalent daily) and five were receiving high-dose corticosteroids (mean \pm SEM dose per day $19 \cdot 4 \pm 2 \cdot 1 \mathrm{mg}$ prednisolone or equivalent).

\section{SERONEGATIVE ARTHRITIDES}

\section{Psoriatic arthritis}

Eight patients were studied of whom five were male. Mean age was 34.8 years (range $18-72$ years), and the mean duration of the arthritis and of the psoriasis was 7.3 years (range 1-25 years) and 17.9 years (range 7-51 years) respectively. All were seronegative for rheumatoid factor and all had an erosive, inflammatory, polyarthritis of typical distribution (Duthie, 1970) and evidence of sacroiliac involvement. In five patients there was evidence of characteristic nail dystrophy and in two evidence of periostitis on radiological examination. None of these patients was receiving corticosteroids or chrysotherapy, but all were receiving a wide range of nonsteroidal antiinflammatory drugs and one patient had had a course of methotrexate which had been discontinued 3 months before the study.

\section{Osteoarthrosis}

Twenty-five patients with osteoarthrosis either of the oligoarthritic or polyarthritic type were studied. Seven were male and their mean age was $67 \cdot 4$ years (range $41-84$ years). Most (17) of these patients had severe clinical and radiological osteoarthrosis of the hip joint. None had diabetes or evidence of disease of other major systems; all had a normal erythrocyte sedimentation rate and haemoglobin concentration and all were seronegative for rheumatoid factor. All were receiving analgesic or nonsteroidal anti-inflammatory drugs.

\section{Ankylosing spondylitis}

Seventeen male patients with ankylosing spondylitis, mean age $34 \cdot 2$ years (range 19-63 years), were studied. All of these patients had low back pain and stiffness, radiological evidence of bilateral sacroiliitis and morning stiffness. All were receiving phenylbutazone, indomethacin, or naproxen and none had at any time received radiotherapy. All patients had W.27 tissue type antigens. Four patients had had uveitis and six had a peripheral arthritis but none had evidence of aortic incompetence.

\section{Tuberculosis}

Sixteen patients with bacteriologically confirmed pulmonary tuberculosis were studied. Twelve of these were male and the mean age of the group was 59.4 years (range 2779 years). All had early active disease as shown by systemic symptoms and chest radiology, and all had recently been started on antituberculous chemotherapy (ethambutol, isoniazid, and/or rifampicin). None of these had clinical evidence of involvement of any other organ system.

\section{Myocardial infarction}

Nine patients were studied within 3 to 5 days of an episode of prolonged typical chest pain followed by sequential cardiographic and serum enzyme changes. Seven of these patients were male, mean age $54 \cdot 2$ years (range 46-67 years). This was the first episode of infarction in all

Table II Immunoreactive gastrin in nonrheumatoid inflammatory disease

\begin{tabular}{|c|c|c|c|c|c|c|c|c|}
\hline & Controls & $\begin{array}{l}\text { Rheumatoid } \\
\text { arthritis }\end{array}$ & Psoriasis & $S L E$ & $\begin{array}{l}\text { Ankylosing } \\
\text { spondylitis }\end{array}$ & Osteoarthrosis & $T B$ & $\begin{array}{l}\text { Myocardial } \\
\text { infarction }\end{array}$ \\
\hline $\begin{array}{l}\text { Mean IRG } \\
\text { SD } \\
\text { SEM }\end{array}$ & $\begin{array}{l}56 \\
72 \cdot 4 \\
8\end{array}$ & $\begin{array}{l}312 \\
463 \cdot 0 \\
57\end{array}$ & $\begin{array}{l}68 \\
45 \cdot 3 \\
16\end{array}$ & $\begin{array}{l}67 \\
69 \cdot 0 \\
14\end{array}$ & $\begin{array}{l}25 \\
23 \cdot 68 \\
6\end{array}$ & $\begin{array}{l}59 \\
53 \cdot 4 \\
11\end{array}$ & $\begin{array}{l}86 \\
33 \cdot 1 \\
16\end{array}$ & $\begin{array}{l}90 \\
47 \cdot 3 \\
16\end{array}$ \\
\hline
\end{tabular}


these patients and in none was serum lipoprotein abnormalities likely to be aetiological in the infarction (Rooney, Ballantyne, and Buchanan, 1975a). When blood was drawn for serum IRG concentrations these patients had all been pain free for at least 72 hours.

\section{CONTROLS}

The controls used for this study were 102 patients attending an accident and emergency department with minor trauma who gave no clinical history of major systemic disease, particular attention being paid to disease of the locomotor, gastrointestinal, and genitourinary systems. Their mean age was $47 \cdot 3$ years (range $21-74$ years).

\section{DRUG STUDIES}

The effect of 14 days' treatment with a single anti-inflammatory drug on the serum IRG concentration was studied in small groups of patients with 'classical' rheumatoid arthritis. The drugs used were soluble aspirin $3 \mathrm{~g}$ daily, indomethacin $200 \mathrm{mg}$ daily, phenylbutazone $300 \mathrm{mg}$ daily, tetracosactrin $0.5 \mathrm{mg}$ daily, and ascorbic acid $500 \mathrm{mg}$ daily. Clinical assessment on day 0 and day 7 included articular index, pain index, and patient assessment numerically graded. Blood was withdrawn at the same time for measurement of IRG concentration and erythrocyte sedimentation rate.

\section{IMMUNOREACTIVE GASTRIN}

In all instances serum for IRG estimation was withdrawn after a 14-hour overnight fast. IRG was assayed by a sensitive and specific radioimmunoassay. This depends upon specific antibody raised in rabbits to synthetic human gastrin I. Radiolabelling of the hormone is accomplished by a modification of the chloramine $\mathrm{T}$ method (Hunter and Greenwood, 1962). Separation of free from antibody-bound hormone is achieved using dextrancoated charcoal (Buchanan and McCarroll, 1971). The sensitivity of this method is greatest below $600 \mathrm{pg} / \mathrm{ml}$ and the lower limit of reliable detection is of the order of $10 \mathrm{pg} / \mathrm{ml}$. The antibody used detects the heptadecapeptide as well as 'big' and 'big big' gastrin (Yalow and Berson, 1972) and there is minimal cross reactivity with cholecystokinin pancreozymin.

\section{Results}

The results are shown in Table II and the Figure. If we take the IRG in the patients with rheumatoid $\triangle$ arthritis as belonging to a single population the mean $\%$ level would be $312 \mathrm{pg} / \mathrm{ml} \pm 463.0 \mathrm{pg} / \mathrm{ml}$ (SD). This $\vec{\circ}$ is significantly greater than the mean level in the control group of normal subjects $(56 \pm 133.6 \mathrm{pg} / \mathrm{ml} \vec{\omega}$ SD) $(\mathrm{t}=5.46 ; 0.005<\mathrm{P}<0.001)$. The mean level of IRG in all other disease groups was within the $\bar{c}$ normal range and no patient with osteoarthrosis, $w$ systemic lupus erythematosus, psoriatic arthritis, $\rightarrow$ ankylosing spondylitis, tuberculosis, or myocardial $\overrightarrow{0}$ infarction had a serum IRG concentration greater 0 than $400 \mathrm{pg} / \mathrm{ml}$ (i.e. the maximal normal control value) (Table II).

Confirming our previous experience (Rooney and $\frac{D}{O}$ others, 1973b), within this group of patients with rheumatoid arthritis there are some patients with markedly raised values and a much larger proportion $\vec{\varphi}$ with values for IRG concentration which fall with the normal range. If the IRG values of the contra subjects are plotted arithmetically a skew distribution is obtained with a coefficient of skewness of $20: \bar{\theta}$ and a coefficient of kurtosis of 50.05 (Spiegel, 1972). In a completely normal distribution both these values should approach zero. The Figure shows these

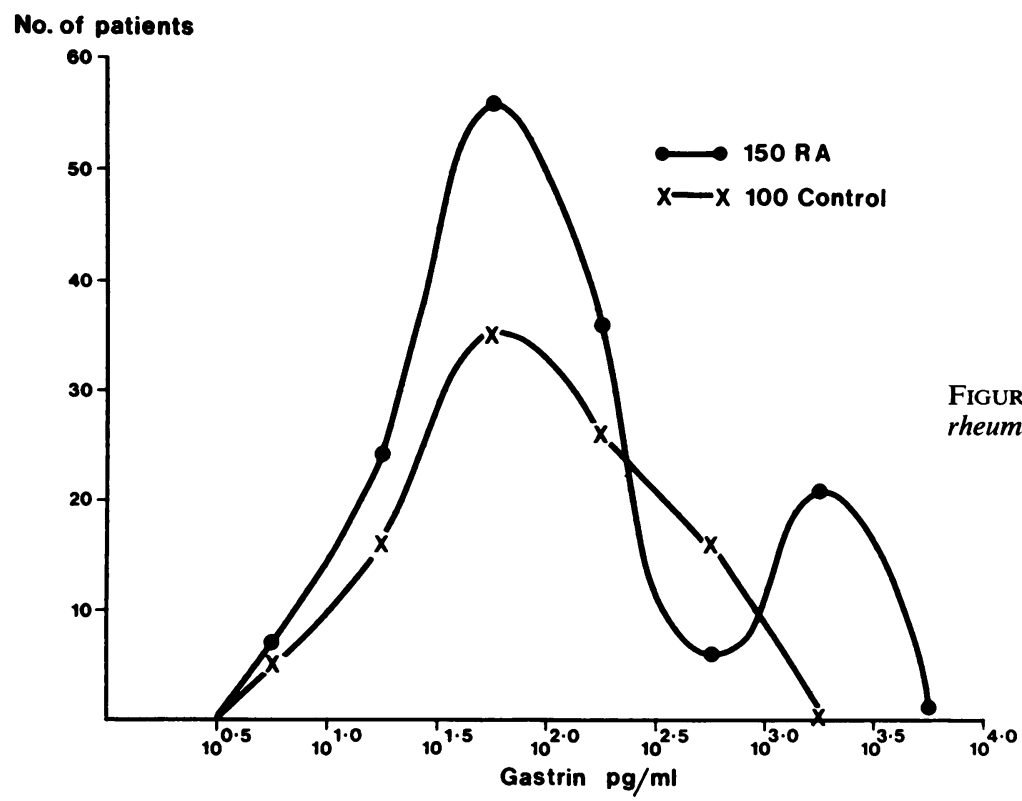

FIGURE Distribution curve of IRG in rheumatoid arthritis and control subjects 
Table III Results of serum IRG concentration after standard dose drug regimens

\begin{tabular}{|c|c|c|c|c|c|c|c|}
\hline \multirow[t]{2}{*}{ Drug } & \multirow[t]{2}{*}{ Dose } & \multicolumn{2}{|c|}{$\begin{array}{l}\text { Immunoreactive gastrin } \\
(p g / m l)(\text { mean } \pm S E M)\end{array}$} & \multicolumn{2}{|c|}{$\begin{array}{l}\text { Articular index } \\
(M e a n \pm S E M)\end{array}$} & \multicolumn{2}{|c|}{$\begin{array}{l}E S R \\
(M e a n \pm S E M)\end{array}$} \\
\hline & & Pre & Post & Pre & Post & Pre & Post \\
\hline $\begin{array}{l}\text { Aspirin } \\
\text { Indomethacin } \\
\text { Phenylbutazone } \\
\text { Tetracosactrin } \\
\text { Ascorbic acid }\end{array}$ & $\begin{array}{c}4 \mathrm{~g} / \mathrm{d} \\
200 \mathrm{mg} / \mathrm{d} \\
300 \mathrm{mg} / \mathrm{d} \\
2 \cdot 5 \mathrm{mg} / \mathrm{d} \\
600 \mathrm{mg} / \mathrm{d}\end{array}$ & $\begin{array}{l}102 \pm 11 \\
152 \pm 27 \\
127 \pm 9 \\
111 \pm 9 \\
172 \pm 33\end{array}$ & $\begin{array}{l}111 \pm 9 \\
143 \pm 22 \\
138 \pm 11 \\
118 \pm 7 \\
162 \pm 24\end{array}$ & $\begin{array}{r}15 \cdot 6 \pm 3.2 \\
17 \cdot 4 \pm 3 \cdot 4 \\
5 \cdot 3 \pm 4 \cdot 0 \\
17 \cdot 3 \pm 3 \cdot 2 \\
12 \cdot 1 \pm 1 \cdot 1\end{array}$ & $\begin{array}{r}12 \cdot 8 \pm 2 \cdot 4 \\
16 \cdot 4 \pm 2 \cdot 8 \\
7 \cdot 2 \pm 3 \cdot 0 \\
12 \cdot 1 \pm 3 \cdot 2 \\
12 \cdot 2 \pm 1 \cdot 7\end{array}$ & $\begin{array}{r}11 \cdot 4 \pm 3 \cdot 2 \\
8 \cdot 2 \pm 3 \cdot 2 \\
15 \cdot 1 \pm 3 \cdot 9 \\
15 \cdot 2 \pm 1 \cdot 8 \\
15 \cdot 8 \pm 3 \cdot 2\end{array}$ & $\begin{array}{l}11 \cdot 2 \pm 3 \cdot 7 \\
11.2 \pm 2.4 \\
16.4 \pm 5 \cdot 2 \\
12 \cdot 1 \pm 3.4 \\
14.9 \pm 2.4\end{array}$ \\
\hline
\end{tabular}

same results plotted on a logarithmic scale and in this way the distribution is normalized, giving a coefficient of skewness of 3.15 and a coefficient of kurtosis of $2 \cdot 54$. The Figure also shows the IRG results obtained in the rheumatoid patients. Most of these results parallel the distribution of the controls but the curve can be seen to be bimodal with a second peak of incidence between $10^{3}$ and $10^{3.5} \mathrm{pg} / \mathrm{ml}$ of immunoreactive gastrin.

Arbitrary division of both the control population and the patients with rheumatoid arthritis at the level of $10^{2.5} \mathrm{pg} / \mathrm{ml}$ IRG shows that of 102 control subjects only two had levels greater than this value whereas of 152 patients with rheumatoid arthritis 33 lay above this level. A $\chi^{2}$ test of these figures suggests that this difference is highly significant $\left(\chi^{2}=\right.$ 20.0; $P<0.001)$. Using this same arbitrary division an $F$ test suggests that the two groups of patients with rheumatoid arthritis are samples of different populations $(F=17 \cdot 15 ; P<0.002)$.

There was no significant relationship between serum IRG concentration and any of the clinical or laboratory tests undertaken in this study. In particular there was no relationship between serum IRG and articular index, erythrocyte sedimentation rate, rheumatoid factor titre, or serum immunoglobulin concentration.

The results of the serum IRG concentration before and after standard dose regimens of aspirin, indomethacin, phenylbutazone, and prednisolone are shown in Table III. It can be seen that no predictable change occurred either in the pre- and postserum IRG concentrations or in the changes in IRG compared with the change in either clinical or laboratory indices. That the drugs were being absorbed is indicated by the clinical effect shown by the changes in assessment indices.

\section{Discussion}

The study of raised serum IRG concentrations in rheumatoid arthritis is becoming more interesting as early possible explanations of the phenomenon are being excluded.

In rheumatoid arthritis anti-inflammatory drugs, which are being used constantly and universally in this disease, seemed to be a likely cause of the immunoreactive hypergastrinaemia. Two observations refute this. In the first place individual studies with these drugs reported here showed that these drugs had no effect whatsoever on the serum IRG concentrations, and serum IRG levels are not raised in inflammatory joint disease of nonrheumatoid origin in patients receiving roughly comparable drug therapy. In the second place we have reported elsewhere (Rooney and others, 1973a) that IRG levels rise when adjuvant arthritis is induced in rats, an experiment in which no anti-inflammatory drug was used. It seems unlikely therefore that this effect is drug induced.

A further possibility was that the high IRG levels in rheumatoid arthritis represented simply another nonspecific acute phase reactant. Again certain observations are contrary to this interpretation. No rise of the serum IRG concentration could be shown in this study in nonarthritic inflammatory or tissuedestructive diseases such as active pulmonary tuberculosis or myocardial infarction. Also the rise in IRG in rheumatoid arthritis is not related to other clinical and laboratory indices of the severity of the inflammatory process at the time of study. Finally, and most remarkably, raised serum IRG levels have not been observed yet in related inflammatory joint diseases such as psoriatic arthritis, systemic lupus erythematosus, or ankylosing spondylitis, an important finding when one considers how few parameters of disease are abnormal, exclusively in rheumatoid arthritis. Although the numbers studied in this present sample are too few to conclude that serum IRG is never raised in these other diseases, they are sufficient to focus our attention on the relationships between raised serum IRG and rheumatoid or adjuvant arthritis.

There remains the early suggestion that the profusion of immunological deviations that occur in rheumatoid arthritis were in some way interfering with the radioimmunoassay. That the most obvious contender, namely IgM rheumatoid factor was not the entity responsible was established in our first result (Rooney and others, 1973b) in which raised 
serum IRG occurred in seronegative patients. It is still possible that IgG rheumatoid factor (Torrigiani and Roitt, 1967) or IgG anti-IgG complexes are responsible, but is less likely when one considers that serum IRG concentrations are not raised in psoriatic arthritis, in which these are known to occur (Tapanes, Rawson, and Hollander, 1972) and in systemic lupus erythematosus, a disease in which a diverse range of antigen-antibody complexes (Kunkel and others, 1961) and of autoantibodies (Hart, 1970) occurs. It is also noteworthy in view of the recent report of interference with radioimmunoassay results of TSH by immunoglobulins (Chapman, Hutton, and Hatter, 1974) that there was no relationship in the present study between serum IRG concentrations and immunoglobulin levels either in the patients with rheumatoid arthritis or in those with systemic lupus erythematosus.

We are therefore left with the observation that raised IRG concentrations in rheumatoid arthritis are unlikely to be due to drugs, although it is fair to point out that studies over a period of 14 days do not exclude a pharmacological effect of compounds which have been used for many years. Nor is it likely that the raised IRG concentrations relate to interfering nonspecific immunoglobulins and they probably do not represent a nonspecific acute phase reactant. A difficult and central problem is posed by the coexistence of markedly raised serum IRG together with normal gastric acid output and normal gastric mucosal histology (Rooney and others, 1974). There is no evidence of end-organ failure, so either the hormone measured by radioimmunoassay is not biologically active or its action is blocked in some way.
The recent observations on the heterogeneity of circulating gastrin (Walsh, Debas, and Grossman, 1973) have suggested that the larger molecules in the circulation have a lesser biological activity than those smaller entities such as 'G-17-I' and 'G-17-II' or 'G-34-I' and 'G-34-II'. Until full gel filtration studies and bioassay studies are completed the possibility remains that the high levels of IRG observed in rheumatoid arthritis are due to large biologically inert forms of the hormone.

Biological blockade is also possible and the recent observations that prostaglandins can inhibit the effect of gastrin (Karim and others 1973) and the implication of compounds of this type in the inflammatory reaction (Greaves, Sondergaard, and McDonald Gibson, 1971) suggest one possible mechanism of this type.

Perhaps the most exciting observation in the present study is that within the population of rheumatoids, which we currently view as 'homogeneous' by the criteria of seropositivity joint erosions, and a chronic peripheral, inflammatory polyarthritis, by at least one criterion there appears to exist a bimodal distribution. It is now essential to determine if these subgroups exhibit any difference, clinically, pharmacologically, or immunologically; and the result encourages us to pursue our studies to look for othe 'handles' by which we can more definitively sub? classify this enigmatic condition which may represent like 'Bright's kidney', a limited tissue response to widely different initiating mechanisms.

We gratefully acknowledge the help of Drs. R. Hume and $R$. Borthwick who allowed us to study patients under their care.

\section{References}

Buchanan, K. D., AND MCCARroll, A. M. (1971) 'Separation techniques', in 'Radioimmunoassay Methods', eds. K. E. Kirkham and W. M. Hunter, p. 136. Churchill Livingstone, London.

Chapman, C., Hutton, W. N., and Hatter, C. J. (1974) Clin. Sci. and molec. Med., 46, 651 (The interference of human IgG with double antibody radioimmunoassay of thyrotrophic hormone and its clinical significance)

DuthIE, J. J. R. (1970) 'Psoriatic arthritis', in 'Textbook of the Rheumatic Diseases', ed. W. S. C. Copeman, p. 315. Livingstone, Edinburgh and London

Greaves, M. W., SondergaARD, J., AND MCDonald Gibson, W. (1971) Brit. med. J., 2, 458 (Recovery of prostaglandins in human cutaneous inflammation)

HART, F. D. (1970) 'The diffuse collagen (connective tissue) disorders', in 'Textbook of the Rheumatic Diseases', ed. W. S. C. Copeman, p. 574. Livingstone, Edinburgh and London

Hunter, W. M., AND GreenwoOd, F. C. (1962) Nature, 194, 495 (Preparation of ${ }^{133}$ iodine labelled human growth hormone of high specific activity)

Karim, S. M. M., Carter, D. C., Bhana, D., and Adaikan-Ganesan, P. (1973) Brit. med. J., 1, 143 (Effect of orally administered prostaglandin E2 and its 15 methyl analogues on gastric secretion)

Kunkel, H. G., Muller-Eberhard, H. J., Fudenberg, H. H., AND Tomasi, T. B. (1961) J. clin. Invest., 40, 117 (Gamma globulin complexes in rheumatoid arthritis and certain other conditions)

Lee, P., Sturrock, R. D., Kennedy, A. C., And Dick, W. C. (1973) Curr. med. Res. and Opin., 1, 427 (The evaluation of anti-rheumatic drugs)

Rooney, P. J., Ballantyne, D., AND Buchanan, W. W. (1975a) 'Disorder of the locomotor system associated with abnormalities of lipid metabolism and the lipoidiss', in 'Clinics in Rheumatic Diseases' ed. E. G. L. Bywaters, p. 163. Saunders, London 
- Dick, W. C., ImRie, R. C., AND Buchanan, K. D. (1973a) Nature, 246, 497 (An animal model for the study of the relationship between immunoreactive gastrin and inflammatory arthritis)

- Dow, T. G. B., Brooks, P. M., Dick, W. C., And Buchanan, K. D. (1975b) Amer.J. Obstet. Gynec., 122, 834 (Immunoreactive gastrin and gestation)

-, OAKley, C., Sturrock, R. D., Dick, W. C., Hayes, J. R., and Buchanan, K. D. (1974) Lancet, 1, 592 (Effect of carbenoxolone upon immunoreactive secretin in patients with rheumatoid arthritis)

—-, Vince, J., Kennedy, A. C., Webb, J., Lee, P., Dick, W. C., Buchanan, K. D., Hayes, J. R., Ardill, J., AND O'CoNNOR, F. (1973b) Brit. med. J., 1, 752 (Hypergastrinaemia in rheumatoid arthritis: disease or iatrogenesis)

Ropes, M. W., Bennet, G. A.. Cobb, J., Jacox, R., And Jessar, R. A. (1959) Ann. rheum. Dis. 18, 49 (1958 revision of diagnostic criteria for rheumatoid arthritis)

SpIEgel, M. R. (1972) 'Moments, skewness and kurtosis', in 'Theory and Problems of Statistics', p. 89. McGrawHill, New York

Tapanes, F. J., Rawson, A. S., AND Hollander, J. L. (1972) Arth. and Rheum., 15, 153 (Serum anti-immunoglobulins in psoriatic arthritis as compared with rheumatoid arthritis)

ToRrigiani, G., AND RoITt, I. M. (1967) Ann. rheum. Dis., 36, 334 (Antiglobulin factors in sera from patients with rheumatoid arthritis and normal subjects)

Walsh, J. H., Debas, H. T., AND Grossman, M. I. (1974) J. clin. Invest., 54, 477 (Pure human big gastrin: immunochemical properties disappearance half-time and acid stimulating action in dogs)

Whaley, K., Williamson, J., Chisholm, D. M., WebB, J., Mason, D. K., and Buchanan, W. W. (1973) Quart. J. Med., 42, 279 (Sjogren's syndrome. 1. Sicca components)

Yalow, R. S., AND Berson, S. A. (1972) Biochem. Biophys. Res. Commun. 48, 391 (And now 'big big' gastrin) 